\title{
Eddy covariance methane measurements at a Ponderosa pine plantation in California
}

\author{
C. J. P. P. Smeets ${ }^{1}$, R. Holzinger ${ }^{1}$, I. Vigano ${ }^{1}$, A. H. Goldstein ${ }^{2}$, and T. Röckmann ${ }^{1}$ \\ ${ }^{1}$ Institute for Marine and Atmospheric research Utrecht, Princetonplein 5, 3584 CC, Utrecht, The Netherlands \\ ${ }^{2}$ University of California, Berkeley, Department of Environmental Science, Policy and management, USA
}

Received: 15 December 2008 - Published in Atmos. Chem. Phys. Discuss.: 26 February 2009

Revised: 19 June 2009 - Accepted: 25 September 2009 - Published: 3 November 2009

\begin{abstract}
Long term methane flux measurements have been mostly performed with plant or soil enclosure techniques on specific components of an ecosystem. New fast response methane analyzers make it possible to use the eddy covariance (EC) technique instead. The EC technique is advantageous because it allows continuous flux measurements integrating over a larger and more representative area including the complete ecosystem, and allows fluxes to be observed as environmental conditions change naturally without disturbance. We deployed the closed-path Fast Methane analyzer (FMA) from Los Gatos Research Ltd and demonstrate its performance for EC measurements at a Ponderosa pine plantation at the Blodgett Forest site in central California. The fluctuations of the $\mathrm{CH}_{4}$ concentration measured at $10 \mathrm{~Hz}$ appear to be small and their standard deviation is comparable to the magnitude of the signal noise ( \pm 5 ppbv). Consequently, the power spectra typically have a white noise signature at the high frequency end (a slope of +1 ). Nevertheless, in the frequency range important for turbulent exchange, the cospectra of $\mathrm{CH}_{4}$ compare very well with all other scalar cospectra confirming the quality of the FMA measurements are good for the EC technique. We furthermore evaluate the complications of combined open and closed-path measurements when applying the Webb-Pearman-Leuning (WPL) corrections (Webb et al., 1980) and the consequences of a phase lag between the water vapor and methane signal inside the closed path system. The results of diurnal variations of $\mathrm{CH}_{4}$ concentrations and fluxes are summarized and compared to the monthly results of process-based model calculations.
\end{abstract}

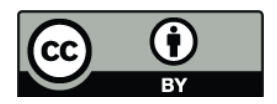

Correspondence to: C. J. P. P. Smeets (c.j.p.p.smeets@uu.nl)

\section{Introduction}

Methane $\left(\mathrm{CH}_{4}\right)$ is the predominant hydrocarbon in the Earth's atmosphere. Although its abundance is far less than that of carbon dioxide $\left(\mathrm{CO}_{2}\right)$, its greenhouse warming potential is 21 times higher per molecule on a 100 year time horizon resulting in a $18 \%$ contribution to the total anthropogenic radiative forcing from greenhouse gases (IPCC, 2007). Current estimates of some of the individual source and sink magnitudes in the $\mathrm{CH}_{4}$ global budget have significant uncertainties that need to be resolved. In particular, there is scientific controversy over both the magnitude and direction of the $\mathrm{CH}_{4}$ flux between forests and the atmosphere, and data to solve this controversy are scarce. The major uncertainty is for tropical forests that comprise a large part of all forested land and are the dominant components of the terrestrial biosphere-atmosphere exchange of trace gases. A recent publication by Frankenberg et al. (2005) showed that satellite data gave about $4 \%$ higher methane concentrations over tropical rainforests in the Amazon region than estimates from a global chemistry transport model. In line with this, airplane and ground measurements by Braga do Carmo et al. (2006) and Miller et al. (2007), respectively, present unexpected large methane emissions from tropical rainforests in the Amazon region (2-21 mg CH $4 \mathrm{~m}^{-2} \mathrm{~d}^{-1}$ and $20-35 \mathrm{mg}$ $\mathrm{CH}_{4} \mathrm{~m}^{-2} \mathrm{~d}^{-1}$, respectively). Apart from wetlands, other unknown sources of methane emissions are thought to be important contributors as well. Recent laboratory results e.g. from Keppler et al. (2005), Keppler et al. (2008) and Vigano et al. (2008) suggest that plants may be direct emitters of $\mathrm{CH}_{4}$.

Long term methane flux measurements in forested areas have been mostly performed using dynamic enclosure (or chamber) techniques for individual ecosystem components such as plants or soils (e.g., Singh et al., 1997; Kiese et al., 2003; Verchot et al., 2000; Kutzbach et al., 2007). While

Published by Copernicus Publications on behalf of the European Geosciences Union. 
these techniques can be simple and relatively inexpensive to operate, they are not continuous and are prone to a variety of potential errors (e.g., Kutzbach et al., 2007). Moreover, enclosure techniques observe fluxes for very small surface areas that are not necessarily representative of the whole ecosystem and can be easily disturbed by the measurement enclosure itself. For example, Simpson et al. (1999) and Sinha et al (2007) measured methane fluxes in boreal forests with chambers and exclusively detected net uptake of $\mathrm{CH}_{4}$, while fluxes measured from micrometeorological towers showed the importance of spatial source and sink heterogeneity and demonstrated that the forest as a whole was a net source.

The eddy covariance (EC) technique is ideally suited for continuous flux measurements integrating over a larger and more representative area including the complete ecosystem, allowing fluxes to be observed as environmental conditions change naturally without disturbance. Examples of methane analyzers that have a fast enough response time to perform EC flux measurements are the quantum cascade laser (QCL) spectrometer (Kroon et al., 2007) and the tunable diode laser (TDL) spectrometer (Wille et al., 2008). We employed the closed path DLT-100 Fast Methane analyzer (FMA) from Los Gatos Research (LGR) employing a more recently developed off-axis integrated cavity output spectrometer (ICOS) which is comparatively easy to use and relatively inexpensive. Hendriks et al. (2008) presented the first field data for this type of methane analyzer obtained under medium high flux conditions over a peat meadow area and demonstrated its stability over longer periods and a sufficient high response rate for EC measurements (i.e., $10 \mathrm{~Hz}$ ).

We present a thorough evaluation of the EC data quality of the FMA under low methane flux conditions over a Ponderosa pine plantation at the Blodgett Forest site on the western slope of the Sierra Nevada Mountains in California. We focus on data processing using frequency-dependent response functions with special attention for the complications that arise under low flux conditions, the combination of open and closed-path measurements when applying the WebbPearman-Leuning (WPL) corrections (Webb et al., 1980) and the consequences of a phase lag between the water vapor and methane signal inside the closed path system. The results of diurnal variations of $\mathrm{CH}_{4}$ concentrations and fluxes are summarized and compared to the monthly results of processbased model calculations (Ridgwell et al., 1999).

\section{Experimental set-up}

\subsection{Field area description}

Observations were made from 11 to 19 August 2007 but the presentation of data is limited to the period 14 to 19 August for which we have a continuous time series. The measurements were performed above a Pondorosa pine plantation owned by Sierra Pacific Industries, adjacent to the Univer- sity of California at Berkeley's Blodgett Forest Research Station. The site is situated on the western slope of the Sierra Nevada mountains in California $\left(38.90^{\circ} \mathrm{N}, 120.63^{\circ} \mathrm{W}\right.$, and $1315 \mathrm{~m}$ elevation), $75 \mathrm{~km}$ downwind (northeast) of Sacramento and receives anthropogenically impacted air masses rising from the valley below during the day. The site was planted with Pinus ponderosa L. in 1990, interspersed with a few individuals of Douglas fir, white fir, California black oak, and incense cedar. Average canopy height in July 2007 was about $8 \mathrm{~m}$, and the leaf area index (LAI) was estimated as $5.1 \mathrm{~m}^{2} \mathrm{~m}^{-2}$ (one-sided LAI for the full canopy). The understory was composed primarily of manzanita (Arctostaphylos spp.) and whitethorn (Ceonothus cordulatus) shrubs. Mixing ratios of several trace gases (e.g. carbon monoxide) along with a whole range of meteorological parameters have been measured at the site since 1997. All technical details of the site are reported elsewhere (Goldstein et al., 2000; Misson et al., 2005).

The EC measurements were carried out at the top of a $13.5 \mathrm{~m}$ high scaffolding tower $(z=13.5 \mathrm{~m}), 5.5 \mathrm{~m}$ above the medium dense canopy. The presence of the canopy causes the bottom surface only to take up a small fraction of the total shear stress. In other words, the logarithmic velocity profile has its origin at the level where the canopy-averaged surface stress acts, the so-called displacement height $d$. This length scale is used as a zero reference level in order to obtain the representative measurement height $(z-d)$. Following Wieringa (1993), we assume that $d$ is proportional to the height of the canopy $h$, i.e. $d / h=0.7$, so that the representative measurement height is $z-d=7.9 \mathrm{~m}$.

The instrumentation consisted of a Campbell CSAT3 sonic anemometer, a Campbell FW3 Type E thermocouple, a LICOR LI7500 open-path hygrometer, and a Fast Methane Analyzer (FMA, Los Gatos Research). Raw data was sampled at $10 \mathrm{~Hz}$ using a Campbell CR1000 datalogger and stored on a laptop. Hendriks et al. (2008) demonstrated that the time constant of the FMA is about $0.1 \mathrm{~s}$, hence a sample frequency of $10 \mathrm{~Hz}$ is sufficient. The FMA was operated in a closedpath EC set-up that carries the sampled air through a $20 \mathrm{~m}$ long PVC tube with a $1 \mathrm{~cm}$ inner diameter. The tube inlet was shielded from rain by a funnel that was mounted $0.2 \mathrm{~m}$ behind the sonic anemometer and close to the LI7500. Before the air enters the cavity it passes a Swagelok SS-4FW4 internal filter with a $2 \mu \mathrm{m}$ pore size. The pump is a high flow dry scroll pump XDS-35i from BOC Edwards with a maximum pumping capacity of $5801 \mathrm{~min}^{-1}$ that is placed behind the FMA. The FMA and dry scroll pump were placed in water resistant and ventilated aluminium boxes. The resistance within the system reduces the pumping speed and from the time lag between the sonic anemometer and the FMA signal we estimated it to be about $401 \mathrm{~min}^{-1}$. 


\section{Data processing}

\subsection{Introduction}

Measurements performed with the EC method need several corrections that mostly increase the turbulent flux. In Sect. 3.2 we discuss the general corrections related to the geometry of the EC set-up and the physical separation and limitations of the individual sensors. For some of these corrections we study the frequency-dependent cospectral transfer functions as described by Moore (1986). For example, the correction of the water vapor flux by means of a transfer function is given by

$$
\frac{\Delta F}{F}=1-\int_{0}^{\infty} T_{w q}(f) C_{w q}(f) d f / \int_{0}^{\infty} C_{w q}(f)
$$

with $T_{w q}$ the net system cospectral transfer function associated with sensors of vertical velocity $w$ and quantity $q$, $C_{w q}$ is the atmospheric cospectrum of $w$ and $q$ at natural frequency $f(\mathrm{~Hz})$. It is the product of the response functions associated with sensor frequency response, size and separation. Measuring under low flux conditions leads to relatively high signal noise and its consequences are discussed in Sect. 3.3. The influence of density fluctuations on the measurement of scalar fluxes described by Webb et al. (1980) (the so-called WPL or Webb-Pearman-Leuning corrections) can be quite important and the consequences of the unusual combination of open- and closed sensors are discussed in Sect. 3.4. The latter corrections are not taken into account traditionally and therefore merit extra attention.

\subsection{General corrections}

EC measurements are always subject to imperfect leveling and we use a data rotation to force the individual half hourly averages of the sonic anemometer wind speeds perpendicular to the average wind direction and in the vertical to zero, i.e. $\bar{v}=0$ and $\bar{w}=0$. The sonic temperature flux is corrected for the contamination from humidity fluxes (Schotanus et al., 1983) and the CSAT3 sonic anemometer is corrected internally for the influence of velocity fluctuations.

The physical separation between the sonic anemometer and all other open- and closed path sensors leads to delay times which are detected by a trial and error method that maximizes the covariances. The mean time delay for the closed path system was found to be about $2.6 \mathrm{~s}$. This procedure also corrects for the longitudinal (streamwise) separation of sensors.

The quality of our EC data and several theoretical and empirical sensor response functions are studied by using an ensemble of 87 cospectra. To obtain good quality cospectra for this selection of data we applied the following criteria. After data rotation (i.e. $\bar{v}=0$ and $\bar{w}=0$ ) and in case of a stationary and homogeneous boundary layer in twodimensional and axially symmetric flow, the momentum flux perpendicular to the average wind direction, $\overline{v^{\prime} w^{\prime}}$, should equal zero. In practice this is seldom the case and we therefore limit the ratio of the lateral and longitudinal momentum fluxes to $\left|\overline{v^{\prime} w^{\prime}} / \overline{u^{\prime} w^{\prime}}\right|<0.25$. To obtain realistic fluxes we limit the delay times resolved from the covariance maximization to values between 2.2 and $3.0 \mathrm{~s}$ for $\mathrm{CH}_{4}$ (the average delay time was $2.6 \mathrm{~s}$ ) and between 0 and $0.3 \mathrm{~s}$ for $\mathrm{CO}_{2}$ and $\mathrm{H}_{2} \mathrm{O}$. To obtain sufficiently large fluxes we only select runs with $u_{*}$ (friction velocity) larger than $0.1 \mathrm{~ms}^{-1}$ and obtained during daytime under slightly unstable conditions, i.e. $-0.5<(z-d) / L<0$ with $L=-u_{*}^{3} \theta_{v} / k g \overline{w \theta_{v}}$ the MoninObhukov length with $k$ the von Kármán constant (taken as $0.4), g$ the gravitational acceleration, $\theta_{v}$ the virtual potential temperature, and $\overline{w \theta_{v}}$ the virtual heat or buoyancy flux.

The lateral separation correction (i.e., perpendicular to the mean wind direction) between the sonic anemometer and the LICOR and FMA inlet is calculated by using an optimized spectral transfer function as described in Appendix A1. Inside the sampling tube of a closed-path system lowpass filtering of scalar fluctuations takes place that can lead to considerable high frequency loss (Lenschow and Raupach, 1991). The theoretical transfer function by Lenschow and Raupach (1991) appears to underestimate the actual tube damping in our system in accord with the findings of Aubinet et al. (2001) and Spank and Bernhofer (2008). We corrected for this by adding an empiric correction factor to the original transfer function (see Appendix A2).

\subsection{High frequency noise}

The magnitude of typical 30-min variations of methane concentrations during the experiment was small and its typical midday standard deviation was about equal to the maximum amplitude of the signal noise (i.e., \pm 5 ppbv, the maximum signal amplitude observed over a time interval of 10 samples. It should be noted that part of this noise probably resulted from the high pumping speed in the closed path system that caused pressure fluctuations inside the measurement cell of the FMA. The consequence of a relatively high noise level is a slope of +1 at the high frequency end of the power spectrum, commonly referred to as a white noise spectrum (Stull, 1997).

The cospectrum is much less influenced since the noise is random and does not correlate with vertical wind speed variations. Such filtering capacity of the covariance function was also demonstrated by Wienhold et al. (1995). Nevertheless, noise still partly modifies the high frequency end of our cospectra. In Fig. 1 we plotted ensemble averaged and normalized cospectra for the selection of 87 runs as a function of natural frequency $f$. Note that we did not use the dimensionless frequency $(f z / u)$ to average our cospectra because the wind speed variations within the selection of 87 runs were 


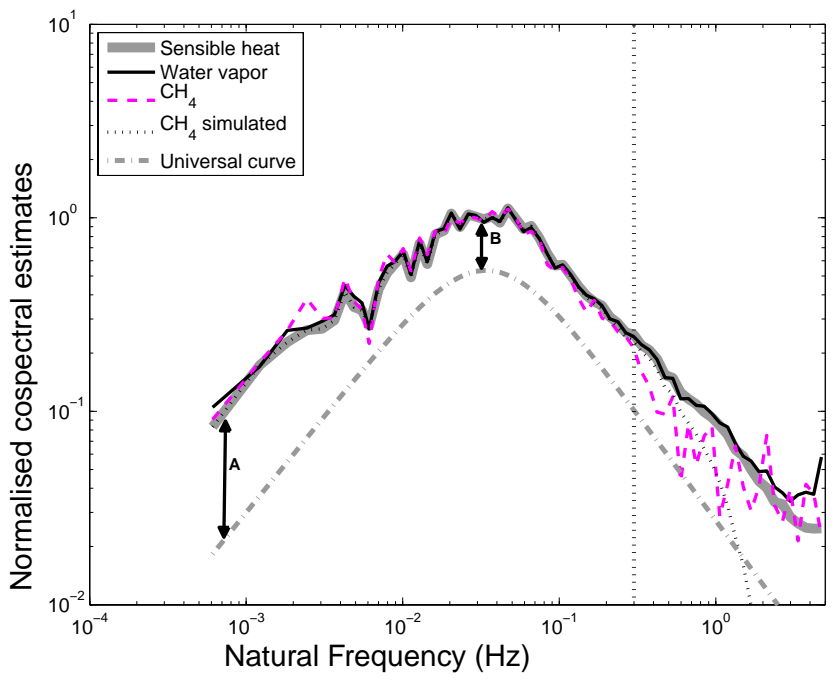

Fig. 1. normalized averaged cospectra from an ensemble of 87 half hour runs. The cospectra for sonic temperature, water vapor and methane flux are plotted as a function of natural frequency. The dotted grey curve $\left(\mathrm{CH}_{4}\right.$ simulated) represents an estimate of the expected shape of the cospectrum of $\mathrm{CH}_{4}$ without the influence of signal noise. The dashed grey curve is the arbitrarily offset near-neutral universal cospectrum (Kaimal et al., 1972; Kaimal, 1973). The different sizes of arrow A and B indicate the deviation between the universal and the measured cospectra at the low frequency end and the dotted vertical line marks the high frequency region where signal noise dominates the cospectrum of $\mathrm{CH}_{4}$. The average stability and wind speed for the ensemble are $z / L=-0.11$ and $\bar{u}=2.5 \mathrm{~m} \mathrm{~s}^{-1}$.

small $\left(\bar{u}=2.5 \pm 0.5 \mathrm{~m} \mathrm{~s}^{-1}\right)$. The cospectra were corrected for sensor line averaging and/or a lateral separation correction when appropriate. The cospectra of sensible heat and water vapor $\left(C_{w T_{s}}\right.$ and $\left.C_{w q}\right)$ overlap and compare very well to the universal Kansas curve for near neutral cospectra (Kaimal et al., 1972; Kaimal, 1973). The universal curve was arbitrarily offset so that a comparison with its slope at low and high frequencies is not obscured by our cospectra. This result is proof for the high quality of our EC measurements. The selected cospectra were obtained under slightly unstable conditions $(\overline{z / L}=-0.11)$ which explains the increase of our cospectra relative to the universal curve at the low frequency end (distance $A>B$ in Fig. 1). The cospectrum of $\mathrm{CH}_{4}$ compares very well to the other cospectra, thereby confirming the good quality of the $\mathrm{CH}_{4}$ measurements by the FMA. However, for frequencies higher than $f=0.3 \mathrm{~Hz}$ (vertical dotted line) the values behave erratic due to the influence of relatively high signal noise as discussed before. Without the influence of this noise $C_{w \mathrm{CH}_{4}}$ is expected to vary as illustrated by the smooth dotted curve. This curve was derived by reducing $C_{w T_{s}}$ with the transfer functions applicable to $C_{w \mathrm{CH}_{4}}$, that is, tube damping, lateral sensor separation and cell volume damping (see Appendix A for a description of the transfer functions).
To obtain correct estimates for the $\mathrm{CH}_{4}$ fluxes we first calculated the methane flux using the selection of cospectral estimates obtained below $f=0.3 \mathrm{~Hz}$. The contribution to the fluxes above $f=0.3 \mathrm{~Hz}$ is estimated from the relative contributions to the sensible heat, water vapor and $\mathrm{CO}_{2}$ cospectra in this frequency range under the assumption of cospectral similarity of scalars (confirmed in Fig. 1). For the ensemble of 87 cospectra the average contribution to the fluxes in the frequency range above $f=0.3 \mathrm{~Hz}$ was about $7 \%$ and varied between 3 and $11 \%$.

\subsection{WPL corrections}

Density fluctuations arising from heat and water vapor fluxes affect the measured flux densities of trace gases, such as moisture and $\mathrm{CO}_{2}$ according to the Webb-Pearman-Leuning (WPL) theory (Webb et al., 1980). The assumptions by WPL (i.e., no net flux of dry air) lead to the prediction of a mean vertical velocity in the presence of heat and/or water vapor fluxes. The vertical flux density $F_{c}$ of trace gas $c$, with density $\rho_{c}$, is given as follows in the WPL formulation

$$
\begin{aligned}
F_{c} & =\overline{\rho_{c}^{\prime} w^{\prime}}+\overline{\rho_{c}} \bar{w} \\
& =\overline{\rho_{c}^{\prime} w^{\prime}}+\overline{\rho_{c}}\left[\frac{\mu}{\overline{\rho_{d}}} \overline{w^{\prime} \rho_{v}^{\prime}}+\frac{(1+\mu \sigma) \overline{w^{\prime} T^{\prime}}}{\bar{T}}\right]
\end{aligned}
$$

with $w$ the vertical velocity, indices $v$ and $d$ indicate the water vapor and the dry air component, respectively, $T$ is the temperature, $\mu$ is the ratio of the molecular masses dry air and water vapor $\left(m_{d} / m_{v}=1.61\right), \sigma$ is the water vapor mixing ratio $\left(\overline{\rho_{v}} / \overline{\rho_{d}}\right)$. An overbar represents a time-mean quantity and a prime represents the deviation from the mean. The first term on the right hand side of Eq. (2) is the measured scalar flux and the second term determines the WPL correction due to the contributions of the water vapor and heat fluxes. For the correction of water vapor and $\mathrm{CO}_{2}$ fluxes Eq. (2) can be applied straightforward and for the closed path system the temperature flux in Eq. (2) can be set to zero since the damping of temperature fluctuations inside the tube of a closed path system is very effective (Leuning and Moncrieff, 1990).

Applying WPL corrections to $\mathrm{CH}_{4}$ fluxes is not straightforward because of the specific set-up of combined open- and closed path sensors. Below we describe in detail two specific corrections applied to the $\mathrm{CH}_{4}$ fluxes that follow from recommendations by Massman (2004) and Ibrom et al. (2007a). For the closed path FMA the only term of concern is the dilution term by water vapor fluctuations in Eq. (2). The fluctuations referred to are those that are present inside the measurement cell where the methane measurement takes place. This leads to the following two problems. First of all, the water vapor fluctuations are measured by an open path sensor in the free atmosphere and second, a significant delay in travel time of water vapor through the tube with respect to other scalars (phase shift effect) has been found in several 
experiments (Laubach and Teichmann, 1996; Aubinet et al., 2000; Clement, 2004; Ibrom et al., 2007a,b).

To estimate the correct water vapor fluxes for use in the WPL corrections for the $\mathrm{CH}_{4}$ fluxes we first calculate the true free atmospheric water vapor flux from the open-path LI7500 data by applying corrections for lateral separation and sensor line averaging. Then we apply inverted corrections for tube damping and cell volume averaging to simulate the attenuation via the closed path system (this reduces the free atmospheric flux between 1 and 5\%). Note that this reduction is small compared to other closed path systems as a result of the combination of a relatively short and wide tube and a high flow rate.

The second effect concerns the phase shift between water vapor and other scalars inside the tube and its dependence on relative humidity which was first quantified by Ibrom et al. (2007b). It is currently not very well known what causes this delay. Ibrom et al. (2007b) noticed that the delay time increased in time due to particles coating to the internal filters or even the entire interior of the intake tube. They hypothesize that the increased damping with $\mathrm{RH}$ relates to the response of particles to a varying $\mathrm{RH}$. The decoupling of scalars and water vapor desynchronizes the actual dilution of $\mathrm{CH}_{4}$ by water vapor inside the closed-path FMA (i.e., the WPL effect). At the time of writing of this paper we did not yet quantify this phase effect for our system. As suggested by Ibrom et al. (2007b), we apply a transfer function to correct for the effect of a phase shift for which the amount of damping depends on the relative humidity (see Appendix B). Throughout the experiment the relative humidity was very low and the maximum day time values were about $\mathrm{RH}=35 \%$ (Fig. 2) leading to a maximum reduction of the water vapor fluxes in the WPL correction of $2-11 \%$.

\section{Results}

In Fig. 2 the meteorological variables temperature, wind speed, relative humidity, net-radiation and wind direction are plotted together with the mixing ratios of $\mathrm{CH}_{4}$ and $\mathrm{CO}$ (measured at the Berkeley Blodgett Forest Research Station). The meteorological variables show the typical diurnal variation that is illustrative for the very regular upslope-downslope flow, described in detail by Lamanna and Goldstein (1999) and Dillon et al. (2002). During summer this circulation is very persistent and present for $72 \%$ of the time (Carroll and Dixon, 2002). Therefore our results should be representative for summer conditions in spite of the limited dataset. During the daytime, upslope flow from the warm Central valley rises along the Western slope of the Sierra Nevada. After sunset a shallow stable boundary layer develops due to radiative cooling of the surface and a layer of cold air flows downslope. Along with this regular wind pattern, the Sacramento urban plume is transported up into the foothills of the Sierra Nevada during daytime. After sunset, the pollutants
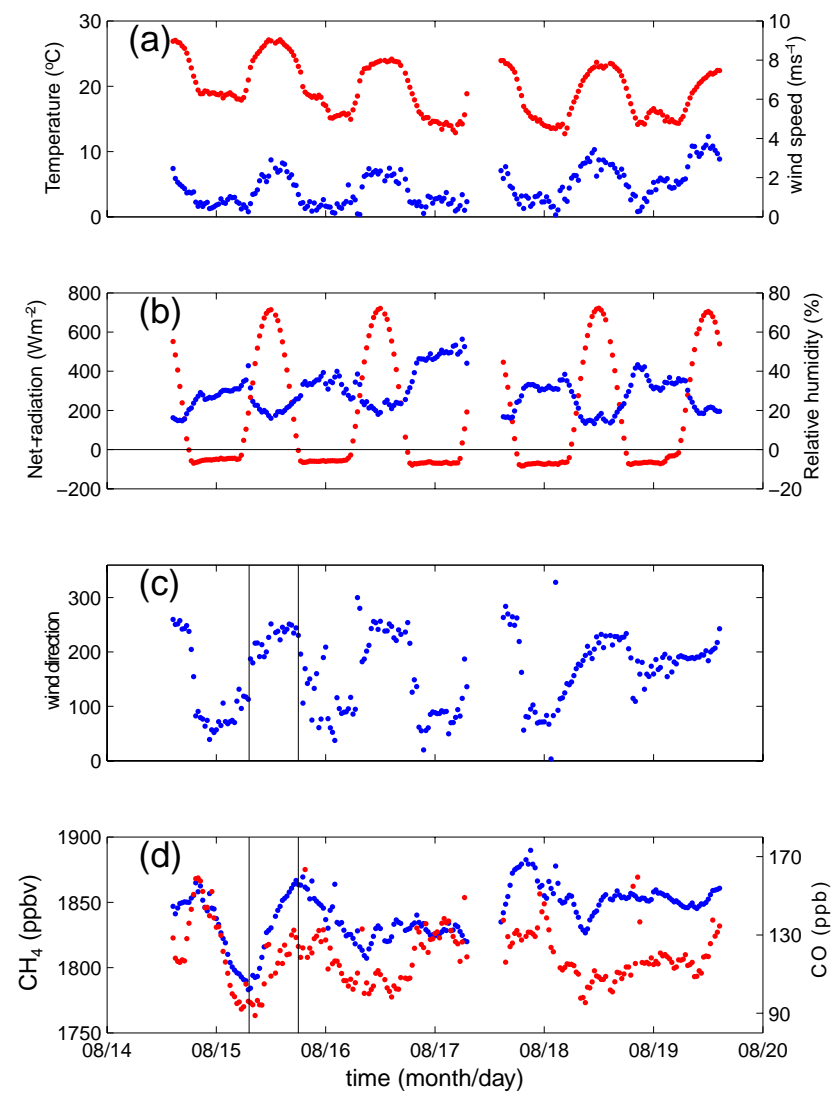

Fig. 2. Time series of (a) temperature (red) and wind speed (blue), (b) net-radiation (red) and relative humidity (blue), (c) wind direction, and (d) $\mathrm{CH}_{4}$ (blue) and $\mathrm{CO}$ (red) concentrations as a function of time. The vertical lines in plot (c) and (d) mark the start and reversal of the upslope flow.

are flushed back towards Central Valley, being replaced by cleaner regional background air from aloft.

The timelines of $\mathrm{CH}_{4}$ and $\mathrm{CO}$ closely follow each other which suggests that both gases originate from the same source regions (Central valley/Sacramento region) and that their mixing ratios are mainly controlled by the diurnal flow patterns. Early in the morning, together with the onset of the upslope flow as indicated by the first vertical solid line in Fig. 2 (at 07:30 h), the concentrations of $\mathrm{CH}_{4}$ and $\mathrm{CO}$ increase simultaneously until the flow turns downslope again at sunset (second vertical solid line at 18:00 h). This diurnal cycle for $\mathrm{CH}_{4}$ and $\mathrm{CO}$ resembles the results from Lamanna and Goldstein (1999) for anthropogenically emitted hydrocarbons.

As $\mathrm{CO}$ emissions mainly originate from combustion, it is likely that $\mathrm{CH}_{4}$ also originates from the same anthropogenic source regions around the Sacramento area. The $\mathrm{CH}_{4}$ concentrations in Fig. 2 vary around the California ambient air background value of about $1835 \mathrm{ppbv}$ (Prinn and Weiss, 2005) with higher values occurring in the pollution plume 

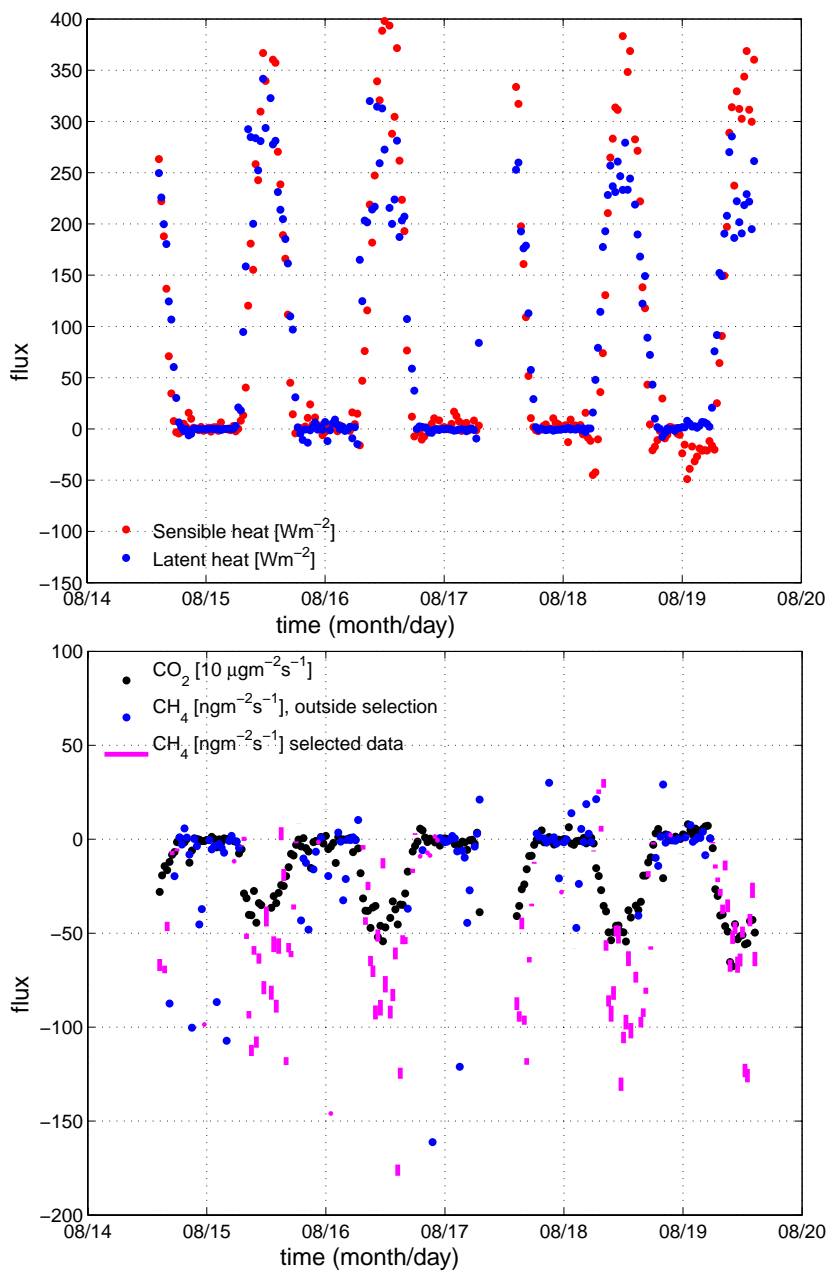

Fig. 3. Time series of sensible and latent heat fluxes (upper panel) and $\mathrm{CO}_{2}$ and $\mathrm{CH}_{4}$ fluxes (lower panel) as a function of time. The vertical size of the bars for $\mathrm{CH}_{4}$ fluxes represent the results with (bottom end of bar) and without (top end of bar) accounting for phase effects in the WPL corrections assuming $\mathrm{RH}=35 \%$ (see text).

from the Sacramento area (late afternoon) and lower ones for the regional background air originating from higher in the Sierra Nevada (just before sunset).

The time series of the various fluxes are plotted in Fig. 3. For $\mathrm{CH}_{4}$ fluxes (pink bars) we only plotted those runs for which a realistic phase shift was obtained from the maximization of covariances (a time lag between 2.2 and $3.0 \mathrm{~s}$ ). The size of a pink bar illustrates the effect of a water vapor phase shift in the WPL corrections (i.e. with and without phase effect corresponds to the largest and smallest negative values of a bar, respectively). For completeness, we also plotted the $\mathrm{CH}_{4}$ fluxes that lie outside the former selection as blue dots. The sensible heat, latent heat and $\mathrm{CO}_{2}$ fluxes all show a clear daily cycle in accord with the fair weather conditions. At night, all fluxes become negligible as the atmosphere becomes stable and turbulence ceases.
The methane fluxes show the same diurnal pattern and are consistently directed downward during daytime. The nighttime $\mathrm{CH}_{4}$ fluxes have noticeable more scatter than all other fluxes, which relates to the larger uncertainty of the $\mathrm{CH}_{4}$ measurements. The daily maximum (downward) $\mathrm{CH}_{4}$ flux varies around $100 \mathrm{ng} \mathrm{m}^{-2} \mathrm{~s}^{-1}$ (or $8.6 \mathrm{mg} \mathrm{m}^{-2} \mathrm{day}^{-1}$ ) and the average obtained during daytime (i.e., between 08:00 and 17:00 h) is about $67 \mathrm{ng} \mathrm{m}^{-2} \mathrm{~s}^{-1}\left(6.0 \mathrm{mg} \mathrm{m}^{-2} \mathrm{day}^{-1}\right)$. The daily mean value for the whole period was $29 \mathrm{ng} \mathrm{m}^{-2} \mathrm{~s}^{-1}$ $\left(2.5 \mathrm{mg} \mathrm{m}^{-2} \mathrm{day}^{-1}\right)$. These values were calculated accounting for water vapor phase effects in the WPL corrections assuming $\mathrm{RH}=35 \%$.

To illustrate the importance of the various corrections to the WPL effect on $\mathrm{CH}_{4}$ fluxes we give some examples for the ensemble of 87 runs. Taking the free atmospheric water vapor flux for the calculation of the WPL effect reduces the average downward $\mathrm{CH}_{4}$ flux from 214 to $56 \mathrm{ng} \mathrm{m}^{-2} \mathrm{~s}^{-1}$ (a reduction of 74\%) and reducing this water vapor flux with the corrections for tube damping/volume averaging slightly increases the $\mathrm{CH}_{4}$ flux to $61 \mathrm{ng} \mathrm{m}^{-2} \mathrm{~s}^{-1}$. We now take the latter result as a reference to study the effects of a phase shift. Taking $\mathrm{RH}=35 \%$, the phase shift increases the $\mathrm{CH}_{4}$ flux further to $68 \mathrm{ng} \mathrm{m}^{-2} \mathrm{~s}^{-1}$. The very low values of RH limit the effect of a phase shift to a $10 \%$ increase of the $\mathrm{CH}_{4}$ flux. However, the influence of the phase effect increases exponentially with RH. Hence, in the hypothetic case of a tropical forest with typical daytime values of $\mathrm{RH}=80 \%$ even in the dry season, the water vapor flux in the WPL correction would reduce $30 \%$ which increases the $\mathrm{CH}_{4}$ flux to $99 \mathrm{ng} \mathrm{m}^{-2} \mathrm{~s}^{-1}$, i.e., an increase of $60 \%$. Such a large sensitivity of WPL corrections to $\mathrm{RH}$ and the way it is implemented is typical for our experiment where the $\mathrm{CH}_{4}$ fluxes are relatively small compared those for water vapor. When we apply the free atmospheric water vapor flux in the WPL correction for example to the $\mathrm{CO}_{2}$ fluxes these only reduce about $20 \%$ while it was $74 \%$ for the $\mathrm{CH}_{4}$ fluxes. Hence, depending on the atmospheric conditions and the trace gases sampled, low-pass filtering due to phase effects can potentially be very important and should be quantified properly for any closed-path ECsystem to prevent possible serious underestimation of fluxes through the WPL effects.

Although our time series is limited it was shown to be representative for the very persistent diurnal circulation pattern occurring throughout summer so that a comparison with monthly model results is justified. Ridgwell et al. (1999) used a process-based model to calculate the monthly consumption of atmospheric $\mathrm{CH}_{4}$ by soils. Their average grid cell deposition for the experimental region in the month of August is about $1 \mathrm{mg} \mathrm{CH} \mathrm{m}^{2}$ day $^{-1}$ which is lower than the $\mathrm{CH}_{4}$ fluxes obtained during the Blodgett forest campaign $\left(2.5 \mathrm{mg} \mathrm{m}^{-2} \mathrm{day}^{-1}\right)$. Verchot et al. (2000) and Dutaur and Verchot (2007) suggest that soil texture is an important biochemical control of $\mathrm{CH}_{4}$ oxidation in soils with coarse textured soils consuming $\mathrm{CH}_{4}$ most efficient. Given the very dry conditions at the Blodgett forest site throughout summer, 
it is likely that during our measurements the $\mathrm{CH}_{4}$ uptake by the soil was not limited by oxidation reactions in the soil but through its gas-phase transport capacity, i.e., how well the ground is drained (Verchot et al., 2000). In line with this, the diurnal variation of sub-surface temperatures and humidity were not found to correlate with the measured $\mathrm{CH}_{4}$ fluxes. Since the soil at the Blodgett forest site is very porous (up to $65 \%$ by volume, Goldstein et al., 2000) we therefore expect a high gas diffusivity that is likely to support the observation of relatively high $\mathrm{CH}_{4}$ fluxes.

Most other studies that present $\mathrm{CH}_{4}$ fluxes measured by EC systems obtained much higher values, e.g. an average of $480 \mathrm{ng} \mathrm{m}^{-2} \mathrm{~s}^{-1}$ over a peat meadow area (Hendriks et al., 2008), 50 to $350 \mathrm{ng} \mathrm{m}^{-2} \mathrm{~s}^{-1}$ over Arctic tundra (Wille et al., 2008), and an average of $680 \mathrm{ng} \mathrm{m}^{-2} \mathrm{~s}^{-1}$ over peat grassland (Kroon et al., 2007). We analyzed the detection limit for our $\mathrm{CH}_{4}$ fluxes following the method described by Wienhold et al. (1995) and Kroon et al. (2007) (see Appendix C). Using this method, the average probable detection limit for the ensemble of 87 runs is estimated at $22 \mathrm{ng} \mathrm{m}^{-2} \mathrm{~s}^{-1}$ with a standard deviation of $12 \mathrm{ng} \mathrm{m}^{-2} \mathrm{~s}^{-1}$. The uncertainty for fluxes above the detection limit is on average $26 \%$ according to this method. As a comparison, the uncertainty for all other fluxes obtained with the same method is about $6 \%$, a factor 4 lower.

\section{Conclusions}

We have shown the feasibility of EC measurements at low $\mathrm{CH}_{4}$ flux levels with a Fast Methane analyzer (FMA) during an experiment in a Ponderosa pine plantation at the Blodgett Forest site in California. Even with a relatively high signal to noise ratio the detection limit of the system was about $22 \mathrm{ng} \mathrm{m}^{-2} \mathrm{~s}^{-1}$ with an average uncertainty for fluxes above the detection limit of $26 \%$.

The data treatment procedure is presented in detail. The theoretical transfer function for tube damping by Lenschow and Raupach (1991) was found to underestimate the actual damping in line with findings by Aubinet et al. (2000) and Spank and Bernhofer (2008). The cospectra from the $\mathrm{CH}_{4}$ fluxes compare very well to those from all other scalars and the universal Kansas curve (Kaimal et al., 1972; Kaimal, 1973), demonstrating the quality of the FMA is useful for EC measurements. The relatively high signal to noise ratio caused erratic behavior of the cospectral estimates at the high frequency end above $f=0.3 \mathrm{~Hz}$. This random flux contribution was removed by calculating the $\mathrm{CH}_{4}$ fluxes from cospectral estimates obtained below $f=0.3 \mathrm{~Hz}$. The contribution to the fluxes above $f=0.3 \mathrm{~Hz}$ was estimated from the corrected cospectra of temperature, water vapor and $\mathrm{CO}_{2}$ assuming cospectral similarity of scalars. The effects of desynchronization of the water vapor and $\mathrm{CH}_{4}$ signals inside a closed path sensor, quantitatively described by Ibrom et al. (2007b), are shown to be potentially very important for the Webb-Pearman-Leuning (WPL) correction (Webb et al., 1980) when applied to the relatively small $\mathrm{CH}_{4}$ fluxes. The magnitude of the effect strongly depends on the relative humidity and for California data with a low daytime maximum of $\mathrm{RH}=35 \%$, the $\mathrm{CH}_{4}$ flux increases about $10 \%$. However, in the hypothetic case of a tropical rainforest ecosystem, where RH is typically $80 \%$ during the dry season, the $\mathrm{CH}_{4}$ fluxes would increase about $60 \%$.

The observations at the Blodgett forest site show that the $\mathrm{CH}_{4}$ concentrations vary diurnally with the upslope flow from the polluted valley below in the day, and the downslope flow of cleaner air from aloft during the night with an average value of about $1843 \mathrm{ppbv}$. The $\mathrm{CH}_{4}$ fluxes were consistently directed downward and followed a clear diurnal pattern. Based on an ensemble of 87 30-min flux measurements the average during the daytime was $67 \pm 42 \mathrm{ng} \mathrm{m}^{-2} \mathrm{~s}^{-1}$ and the maximum values varied around $100 \mathrm{ng} \mathrm{m}^{-2} \mathrm{~s}^{-1}$. The daily mean value for the whole period was $29 \mathrm{ng} \mathrm{m}^{-2} \mathrm{~s}^{-1}$ $\left(2.5 \mathrm{mg} \mathrm{m}^{-2} \mathrm{day}^{-1}\right)$. These values are higher than recent monthly estimates from a process-based model study (Ridgwell et al., 1999). We presume that the very dry conditions and porous soil texture at the Blodgett Forest site support a high gas diffusivity of the soil resulting in relatively high $\mathrm{CH}_{4}$ fluxes.

Current estimates of upward directed $\mathrm{CH}_{4}$ fluxes over tropical forest ecosystems by Braga do Carmo et al. (2006), Miller et al. (2007) and Sinha et al (2007) give values of about 20 to 210,280 , and $80 \mathrm{ng} \mathrm{m}^{-2} \mathrm{~s}^{-1}$, respectively. The EC system presented here, with a lower detection limit during this experiment of about $22 \mathrm{ng} \mathrm{m}^{-2} \mathrm{~s}^{-1}$, is expected to be suited for measuring eddy covariance $\mathrm{CH}_{4}$ fluxes even at the low end of this range.

\section{Appendix A}

\section{Frequency response corrections for the EC-system}

\section{A1 Lateral sensor separation}

Following Moore (1986) the effect of lateral separation $s$ between two sensors can be represented by the following cospectral transfer function

$T_{S}(n)=e^{-9.9 n^{1.5}}$

with $n=f s / u$ the normalized frequency and $u$ the wind speed. We derived an optimal value for $s$ by comparing Eq. (A1) with the ratio of ensemble averaged and normalized cospectra of the water vapor flux and the sonic temperature flux. Doing so, we inherently assume negligible flux loss for the sonic temperature flux and co-spectral similarity of scalars in the atmosphere (Ibrom et al., 2007b). The difference in sensor line averaging effects for the sonic and Licor7500 is neglected. We find a good match of the cospectra for $s=0.17 \mathrm{~m}$. Since the inlet of the closed path FMA was 


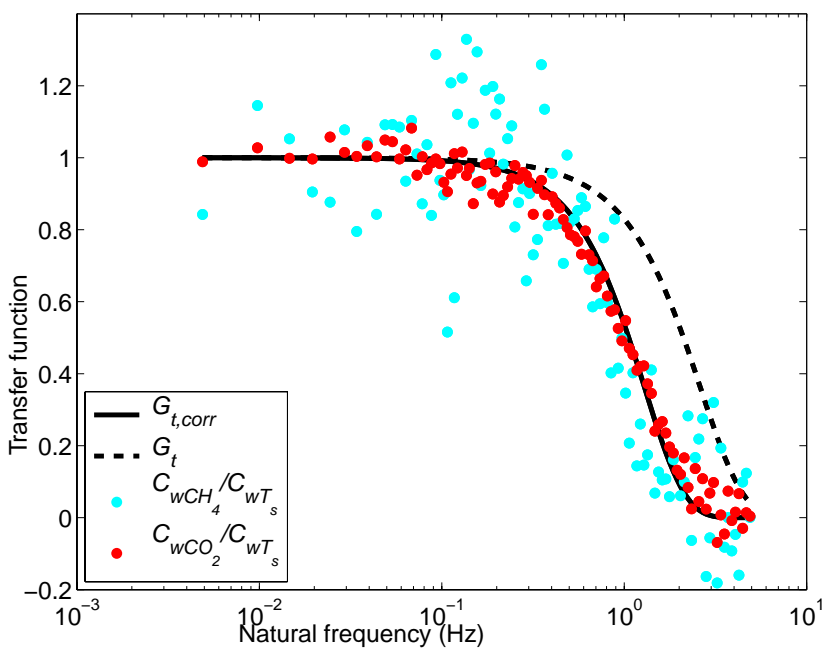

Fig. A1. Transfer functions from an ensemble of 16 half hour runs from an experiment in Cabauw. The empiric transfer functions for damping of the $\mathrm{CO}_{2}$ (red dots, $C_{w \mathrm{CO}_{2}} / C_{w T_{s}}$ ) and the $\mathrm{CH}_{4}$ flux data (blue dots, $C_{w \mathrm{CH}_{4}} / C_{w T_{s}}$ ) are plotted together with the uncorrected $\left(G_{t}\right.$ dashed line) and corrected $\left(G_{t, \text { corr }}\right.$ solid line) predictions from Eq. (A2) as a function of natural frequency. For corrected predictions the exponential term in Eq. (A2) was increased by a factor of 8 .

close to the Licor7500 we use the same procedure to correct for lateral separation of the methane data.

\section{A2 Tube damping}

For turbulent flow in a circular tube with radius $a$ it can be shown (Leuning and King, 1992) that the transfer function is

$G_{t}^{2}=\exp \left(-160 \mathrm{Re}^{-1 / 8} a f^{2} X / U^{2}\right)$,

where $\operatorname{Re}$ is the Reynolds number $(2 a U / v), v$ the kinematic viscosity, $f$ is frequency, $X$ is the tube length (i.e. $20 \mathrm{~m})$, and $U$ the flow speed inside the tube $\left(8.2 \mathrm{~m} \mathrm{~s}^{-1}\right.$ during the California experiment). Equation (A2) applies when $\operatorname{Re}_{c}=2300<\operatorname{Re}<10^{5}$, where $\operatorname{Re}_{c}$ is the critical Reynolds number at which the flow becomes turbulent.

We use the data from an experiment in Cabauw (The Netherlands) to quantify the tube damping characteristics of our EC-system. We employed the same tube and pumping system but additionally connected a closed path Licor6262 analyzer parallel to the FMA. This synchronous set-up allows direct comparison between the $\mathrm{CH}_{4}$ results from the FMA and the $\mathrm{CO}_{2}$ results from the LI6262. The empiric transfer function for tube damping is calculated from the ratio of averaged and normalized cospectra of the $\mathrm{CO}_{2}$ flux (LI6262) and the sonic temperature flux. The cospectrum of the sonic temperature flux (corrected for sensor line averaging) is used as a reference since it does not show significant loss of signal at high frequencies (see Fig. 1). The cospectra of the $\mathrm{CO}_{2}$ and $\mathrm{CH}_{4}$ fluxes were corrected for sensor separation and volume averaging inside the measurement cells (see Sect. A4 below). The cospectrum for $\mathrm{CO}_{2}$ was additionally corrected for signal processing inside the Licor6262 (see Sect. A3 below). The remaining differences between the cospectra of temperature and those of $\mathrm{CO}_{2}$ or $\mathrm{CH}_{4}$ are assumed to represent the tube damping.

In Fig. A1 the ratios of ensemble averaged (16 half hour runs) normalized cospectra from temperature with those of $\mathrm{CO}_{2}\left(C_{w \mathrm{CO}_{2}} / C_{w T_{s}}\right)$ and $\mathrm{CH}_{4}\left(C_{w \mathrm{CH}_{4}} / C_{w T_{s}}\right)$ are compared to the predictions from Eq. (A2) $\left(G_{t}\right)$. First of all, the empiric transfer functions for the $\mathrm{CO}_{2}$ and $\mathrm{CH}_{4}$ cospectra match very well implicating that tube damping of $\mathrm{CH}_{4}$ measurements equals that of the $\mathrm{CO}_{2}$ data from the Licor6262. Second, the prediction from Eq. (A2) clearly underestimates the actual tube damping. Aubinet et al. (2001) also notice a significant underestimation by the theoretical curve (the half-power frequency for the $\mathrm{CO}_{2}$ and $\mathrm{H}_{2} \mathrm{O}$ signal were reduced by about 0.3 and $0.2 \mathrm{~Hz}$, respectively) and appoint this to the effect of filters in the system which is not taken into account in the predictions. To reproduce the empiric transfer function as it is derived from the ratio of cospectra (i.e., $C_{w \mathrm{CO}_{2}} / C_{w T_{s}}$ and $C_{w \mathrm{CH}_{4}} / C_{w T_{s}}$ ) the exponential term in Eq. (A2) was increased by a factor of 8 (solid curve in Fig. A1, $G_{t, \text { corr }}$ ).

\section{A3 Signal processing in the Licor6262}

High frequency attenuation caused by signal processing takes place in the Licor6262 according to Massman (2004). The Licor6262 uses a third-order Bessel filter as an antialiasing filter for signal output, the transfer function, $h_{3 \mathrm{~B}}(\omega)$, is expressed as

$h_{3 \mathrm{~B}}(\omega)=15 /\left(15-6 \Omega^{2}\right)-\mathbf{i}\left(15 \Omega-\Omega^{3}\right)$

where $\mathbf{i}$ is the imaginary unit, $\Omega=3.0824 \tau_{3} B(\omega / 2 \pi)$ and $\tau_{3} B$ is the time constant of the third-order Bessel filter. As in Massman (2004) we use $\tau_{3 B}=0.2 \mathrm{~s}$ in this study.

\section{A4 Volume averaging effects of the measurement cell}

The spectral transfer function related to volume averaging in a measurement cell is (Shimizu, 2007)

$h_{\mathrm{vol}}(\omega)=\frac{\sin ^{2}\left(\omega \tau_{\mathrm{vol}} / 2\right)}{\left(\omega \tau_{\mathrm{vol}} / 2\right)^{2}}$

where $\tau_{\mathrm{vol}}$ is the time constant of the volume averaging effect which is equal to the time needed to fill the chamber and is computed as $\tau_{\mathrm{vol}}=V_{\text {cham }} / P$ with $V_{\text {cham }}$ the volume of the measurement cell, $P$ is the pumping speed in the system $\left(P=38.8\right.$ and $35.51 \mathrm{~min}^{-1}$ for the experiments in California and Cabauw, respectively). The cell volume for the Licor6262 is $1.19 \times 10^{-5} \mathrm{~m}^{3}$ and for the FMA it is $0.55 \times 10^{-3} \mathrm{~m}^{-3}$. 


\section{Appendix B}

\section{Decoupling of signals in a closed-path system}

The amplitude attenuation and decoupling of scalars and water vapor desynchronize the actual dilution of the scalar by water vapor inside the closed-path system (i.e., the WPL effect). This desynchronization of the water vapor signal is simulated as the low pass filtering with a first-order recursive filter (Ibrom et al., 2007b)

$H(f)=\frac{1}{1+\left(f / f_{c}\right)^{2}}$

where $f_{c}$ is the cut-off frequency (the frequency at which the filter reduces the power spectral estimates by a factor 2 ). Ibrom et al. (2007b) present an exponential function that predicts the increase of $f_{c}$ as a function of relative humidity for their EC-system. Moreover, they also demonstrate that the same relation can be used to other EC-systems with very different tube dimensions (i.e., radius and length). From the $\mathrm{CO}_{2}$ measurements performed in Cabauw, mentioned earlier, we estimated that the cut-off frequency for tube damping is $f_{c}=1.042 \mathrm{~Hz}$. The values for RH that we use in this paper are 35 and $80 \%$ which increases the value of $f_{c}$ obtained for $\mathrm{CO}_{2}$ by a factor of 4 and 20 , respectively, according to the results from Ibrom et al. (2007b).

\section{Appendix C}

\section{Probable detection limit of the $\mathrm{CH}_{4}$ fluxes}

For a correct estimate of the closed path measured methane fluxes we estimated its maximum value via a trial and error method that repeatedly calculates covariances for a range of lag times between $w^{\prime}$ and $\mathrm{CH}_{4}^{\prime}$, i.e. the vertical velocity component and the methane concentration, respectively. The standard deviation of the cross covariances far outside the lag time of maximum covariance can be used as an estimate for the flux detection limit (Wienhold et al., 1995; Kroon et al., 2007). In order to obtain a sufficiently large range of tail values, we calculated the covariances for lag times ranging between plus and minus $50 \mathrm{~s}$. The standard deviations of the covariance in the range of lag times from -50 to -40 and +40 to $+50 \mathrm{~s}$ were used as an estimate for the detection limit. The calculation of the detection limit for $\mathrm{CH}_{4}$ fluxes is not straightforward since it includes the influence of water vapor fluxes via the WPL effect. To estimate the correct detection limit from Eq. (2) we therefore use the general formula for the absolute error $\Delta X$ (Fritschen and Gay, 1979) which is equivalent to the total differential of the function $X$ consisting of several independent variables $y_{i}$, each with its own absolute error $\Delta y_{i}$

$\Delta X=\frac{\Delta y_{1} \partial X}{\partial y_{1}}+\frac{\Delta y_{2} \partial X}{\partial y_{2}}+\ldots . .+\frac{\Delta y_{n} \partial X}{\partial y_{n}}$.
The partial derivatives calculated from Eq. (2) for the $\mathrm{CH}_{4}$ and water vapor fluxes are

$\frac{\partial F_{c}}{\partial \overline{\rho_{c}^{\prime} w^{\prime}}}=1$

and

$\frac{\partial F_{c}}{\partial \overline{\rho_{v}^{\prime} w^{\prime}}}=\overline{\rho_{c}} \frac{\mu}{\overline{\rho_{d}}}$

respectively. We assume that the errors in the other terms are small and the errors in the measured $\mathrm{CH}_{4}$ and water vapor fluxes (the $\Delta y_{i}$ 's in Eq. C1) are equal to the detection limit derived from the cross covariance. This method gives a maximum possible error estimate since we combine the individual errors in all variables in the most unfavorable way. A more likely estimate of the total error is obtained when the individual error terms in Eq. (C1) are combined through a least squares approach (Fritschen and Gay, 1979).

The probable detection limit for the selection of 87 runs is $22 \mathrm{ng} \mathrm{m}^{-2} \mathrm{~s}^{-1}$ with a standard deviation of $12 \mathrm{ng} \mathrm{m}^{-2} \mathrm{~s}^{-1}$. This corresponds to a normalized detection limit of about $25 \%$. As a comparison, the normalized detection limit for all other fluxes is about 6\%, hence, a factor 4 lower. As noted before, the results for $\mathrm{CH}_{4}$ are biased by the combination of small variations of $\mathrm{CH}_{4}$ concentrations in a 30-min run and relatively high instrument noise that related to pressure fluctuations as a result of the high pumping speed.

Acknowledgements. We thank Sierra Pacific Industries for the use of their land and the University of California, Berkeley, Center for Forestry, Blodgett Forest Research station for cooperation in facilitating this research. This work was funded by the Dutch NWO, project number 016.071.605.

Edited by: J. Rinne

\section{References}

Aubinet, M., Grell, A., Ibrom, A., Rannik, Ü., Moncrieff, J., et al.: Estimates of the annual net carbon and water exchange of european forests: the euroflux methodology, Adv. Ecol. Res., 30, 113-175, 2000.

Aubinet, M., Chermanne, B., Vandenhaute, M., Longdoz, B., Yernaux, M., and Laitat, E.: Long term carbon dioxide exchange above a mixed forest in the belgain ardennes, Agric Forest Meteorol., 108, 293-315, 2001.

Braga do Carmo, J., Keller, M., Dezincourt Dias, J., Barbaso de Camargo, P., and Crill, P.: A source of methane from the upland forests in the brazilian amazon, Geophys. Res. Lett., 33, L04809, doi:10.1029/2005GL025436, 2006.

Carroll, J. J. and Dixon, A. J.: Regional scale transport over complex terrain, a case study: tracing the sacramento plume in the sierra nevada of california, Atmos. Environ., 36(23), 3745-3758, 2002.

Clement, R.: Mass and energy exchange of a plantation forest in scotland using micrometeorological methods, $\mathrm{PhD}$ thesis, The University of Edinburgh, 597 pp., 2004. 
Dillon, M., Lamanna, M., Schade, G., Goldstein, A., and Cohen, R.: Chemical evolution of the sacramento urban plume: Transport and oxidation, J. Geophys. Res., 107(D5), 4045, doi:10.1029/2001JD000969, 2002.

Dutaur, L. and Verchot, L. V.: A global inventory of the soil $\mathrm{ch}_{4}$ sink, Global Biogeochem. Cycles, 21, GB4013, doi:10.1029/2006GB002734, 2007.

Frankenberg, C., Meirink, J. F., Van Weels, M., Platt, U., and Wagner, T.: Assessing methane emissions from global space-borne obervations, Science, 308, 1010-1014, doi:10.1126/science.1106,644, 2005.

Fritschen, L. J. and Gay, L. W.: Environmental Instrumentation. Springer-Verlag, New York, 216 pp., 1979.

Goldstein, A., Hultman, N., Fracheboud, J., Bauer, M., Panek, J., Xu, M., Qi, Y., Guenther, A., and Baugh, W.: Effects of climate variability on the carbon dioxide, water, and sensible heat fluxes above a ponderosa pine plantation in the sierra nevada (ca), Agric. Forest Meteorol., 101(2-3), 113-129, 2000.

Hendriks, D. M. D., Dolman, A. J., van der Molen, M. K., and van Huissteden, J.: A compact and stable eddy covariance set-up for methane measurements using off-axis integrated cavity output spectroscopy, Atmos. Chem. Phys., 8, 431-443, 2008, http://www.atmos-chem-phys.net/8/431/2008/

Ibrom, A., Dellwik, E., Ejling Larsen, S., and Pilegaard, K.: On the use of the webb-pearman-leuning theory for closed-path eddy correlation measurements, Tellus, 59B, 937-946, 2007 a.

Ibrom, A., Dellwik, E., Flyvbjerg, H., Jensen, N. O., and Pilegaard, K.: Strong low-pass filtering effects on water vapour flux measurements with closed-path eddy correlation systems, Agric. For. Meteorol., 147, 140-156, $2007 \mathrm{~b}$.

IPCC: IPCC Fourth Assessment Report, Climate Change 2007, Cambridge University Press, Cambridge, 996 pp., 2007.

Kaimal, J. C.: Turbulence spectra, length scales and structure parameters in the stable surface layer, Bound. Lay. Meteorol., 4, 289-309, 1973.

Kaimal, J. C., Wyngaard, J. C., Izumi, Y., and Coté, O. R.: Spectral characteristics of surface layer turbulence, Q. J. Roy. Meteorol. Soc., 98, 653-689, 1972.

Keppler, F., Hamilton, J., Braß, M., and Röckmann, T.: Methane emissions from terrestrial plants under aerobic conditions, Nature, 439, 187-191, doi:10.1038/nature04,420, 2005.

Keppler, T., Hamilton, J., McRoberts, W., Vigano, I., Braß, M., and Röckmann, T.: Methoxyl groups of plant pectin as a precursor of atmospheric methane: evidence from deuterium labelling studies, New Phytologist 178, 808-814, doi:10.111/j.14698373.2008.02,411.x, 2008.

Kiese, R., Hewett, B., and Graham, A.: Seasonal variability of $\mathrm{n}_{2} \mathrm{O}$ emissions and $\mathrm{ch}_{4}$ uptake from tropical rainforest siols of queensland, australia, Global Biogeochem. Cycles, 17(2), 1043, doi:10.1029/2002GB00214, 2003.

Kroon, P. S., Hensen, A., Jonker, H. J. J., Zahniser, M. S., van't Veen, W. H., and Vermeulen, A. T.: Suitability of quantum cascade laser spectroscopy for $\mathrm{CH}_{4}$ and $\mathrm{N}_{2} \mathrm{O}$ eddy covariance flux measurements, Biogeosciences, 4, 715-728, 2007, http://www.biogeosciences.net/4/715/2007/.

Kutzbach, L., Schneider, J., Sachs, T., Giebels, M., Nykänen, H., Shurpali, N. J., Martikainen, P. J., and Wilmking, M.: $\mathrm{Co}_{2}$ flux determination by closed-chamber methods can be seriously biased by inappropriate application of linear regression, Bio- geochem., 4, 1005-1025, 2007.

Lamanna, M. and Goldstein, A.: In-situ measurements of c2-c10 vocs above a sierra nevada ponderosa pine plantation, J. Geophys. Res., 104(D17), 21247-21262, 1999.

Laubach, J. and Teichmann, U.: Measuring energy budget components by eddy correlation: Data corrections and application over low vegetation, Beitr. Phys. Atmos., 69(2), 307-320, 1996.

Lenschow, D. H. and Raupach, M. R.: The attenuation of fluctuations in scalar concentrations through sampling tubes, J. Geophys. Res., 96, 15259-15268, 1991.

Leuning, R. and King, K. M.: Comparison of eddy-covarariance measurements of $\mathrm{Co}_{2}$ fluxes by open- and closed-path $\mathrm{Co}_{2}$ analysers, Bound. Lay. Meteorol., 59, 297-311, 1992.

Leuning, R. and Moncrieff, J.: Eddy-covariance $\mathrm{Co}_{2}$ measurements using open- and closed path $\mathrm{co}_{2}$-analysers: correctionsfor analyser water vaapour sensitivity and damping of fluctuations in air sampling tubes, Bound. Lay. Meteorol., 53, 63-76, 1990.

Massman, W. J.: Concerning the measurement of atmospheric trace gas fluxes with open- and closed-path eddy covariance systems: the wpl terms and spectral attenuation, in: Handbook of micrometeorology, edited by: Lee, X., Massman, W. J., and Law, B., Atmospheric and Oceanographic Sciences Library, Kluwer Academic Publishers, pp 133-160, 2004

Miller, J. B., Gatti, L. V., D’Amelio, M. T. S., Crotwell, A. M., Dlugokencky, E. J., Bakwin, P., Artaxo, P. P., and Tans, P. Airborne measurements indicate large methane emissions from the eastern amazon basin, Geophys. Res. Lett., 34, L10809, doi:10.1029/2006GL029213, 2007.

Misson, L., Tang, J., Xu, M., McKay, M., and Goldstein, A.: Influences of recovery from clear-cut, climate variability, and thinning on the carbon balance of a young ponderosa pine plantation, Agric. Forest Meteorol., 130, 207-222, 2005.

Moore, C. J.: Frequency response corrections for eddy correlation systems, Bound. Lay. Meteorol., 37, 17-35, 1986.

Prinn, R. and Weiss, R.: Advanced Global Atmospheric Gases Experiment Sponsored by NASA Upper Atmosphere Research Program. Trinidad Head, California $41^{\circ} \mathrm{N}, 124^{\circ} \mathrm{W}, 03$ May 2005 , http://agage.eas.gatech.edu/data.htm, 2005.

Ridgwell, J. R., Marshall, S. J., and Gregson, K.: Consumption of atmospheric methane by soils: a process-based model, Global Biogeochem. Cycles, 13(1), 59-70, 1999.

Schotanus, P., Nieuwstadt, F. T. M., and De Bruin, H. A. R.: Temperature measurement with a sonic anemometer and its application to heat and moisture fluxes, Bound. Lay. Meteorol., 26, 81-93, 1983.

Shimizu, T.: Practical applicability of high frequency correction theories to $\mathrm{CO}_{2}$ flux measured by a closed-path system, Bound. Lay. Meteorol., 122, 417-438, 2007.

Simpson, I. J., Edwards, G. C., and Thurtell, G. W.: Variations in methane and nitrous oxide mixing ratios at the southern boundary of a canadian boreal forest, Atmos. Environ. 33, 1141-1150, 1999.

Singh, J. S., Singh, S., Raghubanshi, A. S., Singh, S., Kashyap, A. K., and Reddy, V. S.: Effects of soil nitrogen, carbon and moisture on methane uptake by dry tropical forest soils, Plant and Soil, 196, 115-121, 1997.

Sinha, V., Williams, J., Crutzen, P. J., and Lelieveld, J.: Methane emissions from boreal and tropical forest ecosystems derived from in-situ measurements, Atmos. Chem. Phys. Discuss., 7 , 
14011-14039, 2007,

http://www.atmos-chem-phys-discuss.net/7/14011/2007/.

Spank, U. and Bernhofer, C.: Another simple method of spectral correction to obtain robust eddi-covariance results, Bound. Lay. Meteorol., 128, 403-422, 2008.

Stull, R.: An introduction to boundary layer meteorology, D. Reidel Publ. Comp., Dordrecht, The Netherlands, 670 pp., 1997.

Verchot, L. V., Davidson, E. A., Henrique Cattânio, J., and Ackerman, I. L.: Land-use change and biogeochemical controls of methane fluxes in soils of eastern amazonia, Ecosystems, 3, 41$56,2000$.

Vigano, I., van Weelden, H., Holzinger, R., Keppler, F., McLeod, A., and Rckmann, T.: Effect of UV radiation and temperature on the emission of methane from plant biomass and structural components, Biogeosciences, 5, 937-947, 2008, http://www.biogeosciences.net/5/937/2008/.
Webb, E. K., Pearman, G. I., and Leuning, R.: Correction of the flux measurements for density effects due to heat and water vapour transfer, Q. J. Roy. Meteorol. Soc., 106, 85-100, 1980.

Wienhold, F. G., Welling, M., and Harris, G. W.: Micrometeorological measurements and source region analysis of nitrous oxide fluxes from an agricultural soil, Atmos. Environ., 29(17), 22192227, 1995.

Wieringa, J.: Representative roughness parameters for homogeneous terrain, Bound. Lay. Meteorol., 63, 323-363, 1993.

Wille, C., Kutzbach, L., Sachs, T., Wagner, D., and Pfeiffer, E.: Methane emission from siberian arctic polygonal tundra: eddy covariance measurements and modeling, Global Change Biol., 14, 1395-1408, 2008. 